\title{
INTELLIGENT COMPUTING FOR MODELING AXIAL CAPACITY OF PILE FOUNDATIONS
}

\author{
Mohamed A. Shahin \\ BSc, MSc, PhD, MIEAust, MASCE \\ Senior Lecturer, Department of Civil Engineering, \\ Curtin University of Technology, WA 6845, Australia \\ Phone: +61-8-9266 1822; Fax: +61-8-9266 2681 \\ E-mail: m.shahin@curtin.edu.au
}

Canadian Geotechnical Journal 


\title{
Intelligent Computing for Modeling Axial Capacity of Pile Foundations
}

\section{Mohamed A. Shahin}

\begin{abstract}
In the last few decades, numerous methods have been developed for predicting the axial capacity of pile foundations. Among the available methods, the cone penetration test (CPT) based models have been shown to give better predictions in many situations. This can be attributed to the fact that CPT-based methods have been developed in accordance with the CPT results, which have been found to yield more reliable soil properties, hence, more accurate axial pile capacity predictions. In this paper, one of the most commonly used artificial intelligence techniques, i.e. artificial neural networks (ANNs), is utilized in an attempt to develop ANN models that provide more accurate axial capacity predictions for driven piles and drilled shafts. The ANN models are developed using data collected from the literature and comprise 80 driven pile and 94 drilled shaft load tests, as well as CPT results. The predictions from the ANN models are compared with those obtained from the most commonly used available CPT-based methods, and statistical analyses are carried out to rank and evaluate the performance of the ANN models and CPT methods. To facilitate the use of the developed ANN models, they are translated into simple design equations suitable for hand calculations.
\end{abstract}

Keywords: Artificial Neural Networks, Modeling; Axial Capacity, Driven piles, Drilled Shafts. 


\section{Introduction}

The behavior of pile foundations (driven piles and drilled shafts) under axial loading is complex and not yet entirely understood. The geotechnical literature has included many methods, both theoretical and experimental, to predict the ultimate capacity of pile foundations. Due to the difficulty of obtaining undisturbed samples of soils, many pile capacity prediction methods have focused on correlations with in-situ tests, such as the cone penetration test (CPT), standard penetration test (SPT), dilatometer test and pressuremeter test. However, most available methods, by necessity, simplify the problem by incorporating several assumptions associated with the factors that affect the capacity of pile foundations. Consequently, most existing methods fail to achieve consistent success in relation to accurate pile capacity prediction. In this respect, artificial neural networks (ANNs), which do not need incorporation of any assumptions or simplifications, are more efficient.

In recent years, ANNs have been found to solve many problems in the field of geotechnical engineering, and the author has utilized successfully ANNs in different geotechnical engineering applications (e.g. Shahin and Jaksa 2006; Shahin and Indraratna 2006; Shahin et al. 2002a). Interested readers are referred to Shahin et al. $(2001 ; 2009)$, where the pre- and post-2001 papers in applications of ANNs in geotechnical engineering are reported and explained in some detail. ANNs have also been used by other researchers to predict the ultimate capacity of driven piles (e.g. AbuKiefa 1998; Lee and Lee 1996); however, their models were developed using a limited number of data cases and none of the models was based on the more accurate measures of soil properties from the CPT results. More recently, Shahin (2008) has carried out a preliminary investigation for modeling axial capacity of pile foundations using ANNs and has found that ANNs have a good 
potential for predicting ultimate pile capacity. However, the developed model was more suitable for driven piles rather than drilled shafts and has the shortcomings of not distinguishing between different soil types and pile materials. In addition, the model did not consider the difference in measurements between the mechanical and electric CPT results.

In this paper, an attempt is made to overcome the shortcomings of the previous models and sufficient pile load tests and CPT data are used to develop more accurate CPT-based ANN prediction models for the ultimate capacity of driven piles and drilled shafts. The predictive ability of the ANN models is examined by comparing their results with experimental data, and with those obtained from the most commonly used CPT-based pile capacity prediction methods. The robustness of the ANN models is further investigated in sensitivity analyses. Furthermore, statistical analyses, which compare the measured ultimate pile capacities with those obtained from the ANN models and CPT methods, are carried out and used to evaluate and rank the performance of the different methods. The ANN models are then translated into simple design equations for routine use in practice.

\section{Overview of artificial neural networks}

Artificial neural networks (ANNs) are numerical modeling techniques inspired by the functioning of the human brain and nervous system. The ANNs modeling philosophy is similar to that used in the development of more conventional statistical models. In both cases, the purpose of the model is to capture the relationship between a historical set of model inputs and corresponding outputs. However, unlike most available statistical methods, ANNs do not need predefined mathematical equations regarding the relationship between the model inputs and corresponding 
outputs, and they rather use the data alone to determine the structure of the model and unknown model parameters. This enables ANNs to overcome the limitations of existing modeling methods.

The type of ANNs used in this study are multi-layer feed-forward that are trained with the back-propagation algorithm (Rumelhart et al. 1986). A comprehensive description of this type of neural networks is beyond the scope of this paper and can be found in many publications (e.g. Fausett 1994). The typical structure of a multi-layer feed-forward neural network consists of a number of processing elements (also called nodes or neurons) that are fully or partially linked via connection weights. These processing elements are usually arranged in layers: an input layer; an output layer; and one or more layers in between, called hidden layers (see Figure 1). At each processing element, the input from the processing element of the previous layer $\left(x_{i}\right)$ is multiplied by an adjustable connection weight $\left(w_{j i}\right)$, and weighted inputs are summed and a bias $\left(\theta_{j}\right)$ is added or subtracted. This combined input $\left(I_{j}\right)$ is then passed through a non-linear transfer function $(f()$.$) (e.g.$ sigmoidal function or tanh function) to produce the output of the processing element $\left(y_{j}\right)$. Training of a multi-layer feed-forward neural network commences at the input layer, where the network is presented with an actual measured set of data (i.e. the training set) and the output of the network is obtained by utilizing a learning rule. The network output is compared with the desired output from which an error is calculated. This error is then used to adjust the connection weights so that the best input/output mapping is obtained. Once training has been accomplished successfully, the performance of the trained model has to be verified using an independent validation set. 


\section{Development of artificial neural network models}

In this work, two ANN models (one for driven piles and another for drilled shafts) are developed with the aid of the software package NEUFRAME Version 4.0 (Neusciences 2000). The data used to calibrate and validate the ANN models are obtained from the literature and include a series of 80 in-situ driven pile load tests reported by Eslami (1996) and 94 in-situ drilled shaft load tests reported by Alsamman (1995). The tests conduced were located on sites of different soil types and geotechnical conditions, ranging from cohesive clays to cohesionless sands. The driven pile load tests include compression and tension loading conducted on steel and concrete piles driven statically (jacked-in) into the ground. The driven piles used have different shapes (i.e. circular, square and hexagonal) and range in diameter between $250 \mathrm{~mm}$ to $900 \mathrm{~mm}$ and embedment lengths between $5.5 \mathrm{~m}$ to $41.8 \mathrm{~m}$. The drilled shaft load tests were conducted on straight and belled concrete shafts and include compression loading (for straight and belled shafts) and tension loading (for straight shafts only). The drilled shafts used have stem diameters ranging from $305 \mathrm{~mm}$ to $1798 \mathrm{~mm}$ and embedment lengths from $4.5 \mathrm{~m}$ to $27.4 \mathrm{~m}$.

\section{Model inputs and outputs}

Six factors affecting the capacity of driven piles are presented to the ANN as potential model input variables. These include the pile equivalent diameter, $D_{e q}=$ pile perimeter $/ \pi$, embedment length, $L$, weighted average cone point resistance over pile tip failure zone, $\bar{q}_{c-t i p}$, weighted average cone point resistance over pile length, $\bar{q}_{c-s h a f t}$, weighted average cone sleeve

friction over pile length, $\bar{f}_{s}$, and pile material, Material. The ultimate pile capacity, $Q_{u}$, is the 
single model output variable. It should be noted that the following aspects are applied to the input and output variables used in the ANN driven piles model:

- The ultimate pile capacity, $Q_{u}$, is taken to be at the plunging failure for the well-defined failure cases, and at 80\%-criterion (Brinch Hansen 1963) for the cases that failure load is not clearly defined, as suggested by Eslami (1996).

- The pile tip failure zone over which $\bar{q}_{c-t i p}$ is calculated is taken in accordance with Eslami (1996), in which when the pile toe is located in non-homogeneous soil of dense strata with a weak layer above, the influence zone extends to $4 D_{e q}$ below and $8 D_{e q}$ above pile toe. Also, in non-homogeneous soil, when the pile toe is located in weak strata with a dense layer above, the influence zone extends to $4 D_{e q}$ below and $2 D_{e q}$ above pile toe. In homogeneous soil, however, the influence zone extends to $4 D_{e q}$ below and $4 D_{e q}$ above pile toe.

- Because evidence suggests that measurements of cone sleeve friction are less reliable than those of cone point resistance (Briaud and Miran 1992), it is decided to represent the pile shaft resistance not only by using the weighted average cone sleeve friction over the pile length, $\bar{f}_{s}$, but also by incorporating the weighted average cone point resistance over the pile length, $\bar{q}_{c-s h a f t}$. This allows the soil type (classification) to be considered in the ANN model.

- Several CPT tests used in this work include mechanical rather than electric CPT data and thus, it was necessary to convert the mechanical CPT readings into equivalent electric CPT values as the electric CPT is the one that is commonly used nowadays. This is carried out for the cone point resistance using the following correlation proposed by Kulhawy and Mayne (1990):

[1] $\left(\frac{q_{c}}{p_{a}}\right)_{\text {Electric }}=0.47\left(\frac{q_{c}}{p_{a}}\right)_{\text {Mechanical }}^{1.19}$ 
where: $p_{a}$ is the atmospheric pressure, and $p_{a}$ and $q_{c}$ are in $\mathrm{kPa}$. For the cone sleeve friction, the mechanical cone gives higher reading than the electric cone in all soils with a ratio in sands of about 2, and 2.5-3.5 for clays (Kulhawy and Mayne 1990). In the current work, a ratio of 2 is used for sands and 3 for clays. A comparison between the mechanical and electric CPT is beyond the scope of this paper and can be found in Kulhawy and Mayne (1990).

- Finally, before presenting the data to the ANN network, pile material is translated from the text format (i.e. steel or concrete) into arbitrary numeric values (i.e. 1 for steel and 2 for concrete), which neural networks are capable to deal with.

The input variables that are considered to be significant in prediction of the ultimate capacity of drilled shafts include the shaft stem diameter, $D_{\text {stem }}$, shaft base diameter, $D_{\text {base }}$, embedment length, $L$, weighted average cone point resistance over shaft base failure zone, $\bar{q}_{c-b a s e}$, weighted average cone point resistance over shaft length, $\bar{q}_{c-s h a f t}$. These parameters are presented to the ANN model as potential model input variables, and the ultimate drilled shaft capacity, $Q_{u}$, is the single model output variable. It should be noted that the following issues are applied to the input and output variables used in the ANN drilled shafts model:

- The ultimate bearing capacity, $Q_{u}$, for drilled shafts under compression is taken as the axial load measured at a displacement equal to $5 \%$ of shaft base diameter plus the elastic compression of the shaft (i.e. $P L / E A$, where: $P$ is the applied load, $L$ is the shaft length, $A$ is the shaft crosssectional area and $E$ is the shaft elastic modulus). On the other hand, $Q_{u}$ for drilled shafts under tension is defined as the axial load at $12 \mathrm{~mm}\left(0.5^{\prime \prime}\right)$ of displacement. The above criteria for determination of ultimate load are as suggested by Alsamman (1995) and recommended by Reese and O’Neill (1988). 
- The shaft base failure zone over which $\bar{q}_{c-b a s e}$ is calculated is taken in accordance with Alsamman (1995) to be equal to one diameter depth beneath the shaft base.

- In contrast to the driven piles model, records of cone sleeve friction were not available in the database used for the drilled shafts model, thus, $\bar{f}_{s}$ is not considered as an input variable. This is believed not to significantly affect model prediction as measurements of cone sleeve friction are less important and not as reliable as those of cone point resistance, as mentioned previously.

- The majority of records for cone point resistance are mechanical and thus are converted to equivalent electric values using Eqn. (1).

\section{Data division and preprocessing}

The next step in development of the ANN models is dividing the available data into their subsets. As recommended by Masters (1993) and detailed by Shahin et al. (2004), the available data are randomly divided into two statistically consistent sets: training set for model calibration and an independent validation set for model verification. For each of the two ANN developed models, $80 \%$ of the available data are used for training and $20 \%$ for validation. It should be noted that, like all empirical models, ANNs perform best in interpolation rather than extrapolation (Masters 1993), consequently, the extreme values of the available data are included in the training set. The statistics of the data used for the training and validation sets are given in Table 1, which include the mean, standard deviation, minimum, maximum and range. Once data have been divided into their subsets, the input and output variables are pre-processed by scaling them between 0.0 and 1.0 to eliminate their dimension and to ensure that all variables receive equal attention during training. The simple linear mapping of the variables' practical extremes to the neural network's 
practical extremes is adopted for scaling, as it is the most common method for this purpose (Masters 1993). As part of this method, for each variable $x$ with minimum and maximum values $x_{\min }$ and $x_{\max }$, respectively, the scaled value of $x_{n}$ is calculated as follows:

[2] $\quad x_{n}=\left(x-x_{\min }\right) /\left(x_{\max }-x_{\min }\right)$

\section{Model architecture, weight optimization and stopping criterion}

The following step in development of the ANN models is determining the model geometry (i.e. the number of hidden layers and corresponding number of hidden nodes in each layer) and weight optimization (i.e. obtaining the optimal learning rate and momentum term that control the training process). In this work, the optimal model geometry is obtained by utilizing a trial-and-error approach in which the ANN models are trained with initial learning rate and momentum term of 0.2 and 0.8 , respectively, and using one hidden layer with $1,2,3, \ldots$, and $2 I+1$ (where $I$ is the number of input variables) hidden layer nodes. It should be noted that a network with one hidden layer can approximate any continuous function provided that sufficient connection weights are used (Hornik et al. 1989), consequently, one hidden layer is used in the current work. It should also be noted that $2 I+1$ hidden layer nodes is the upper limit needed to map any continuous function for a network with I number of inputs, as discussed by Caudill (1988). The transfer functions used in the hidden and output layers are tanh and sigmoidal transfer functions, respectively. To determine the criterion that should be used to terminate the training process, the normalized mean squared error, NMSE, between the actual and predicted values of pile capacities on the validation set is monitored until no significant improvement in the error occurs. This is achieved at 5000 training cycles (epochs) for 
the driven piles model and at 10,000 for the drilled shafts model. Figure 2 shows the impact of the number of hidden layer nodes on the performance of ANN models. It can be seen that, for the driven piles model, the network with 3 hidden nodes has the lowest prediction error; however, the network with 2 hidden nodes can be considered optimal: its prediction error is not far from that of the network with 3 hidden nodes, and it has fewer connection weights. On the other hand, the number of hidden nodes for the drilled shafts model has less impact on the model predictive ability even a network with only one hidden node is able to adequately map the underlying relationship; however, the network with three hidden nodes has the lowest prediction error.

The weight optimization is determined by training the ANN models that have the lowest prediction error obtained from the abovementioned step. The models are trained with different combinations of learning rates and momentum terms of $0.05,0.1,0.2,0.4,0.6$ and 0.9 , and the results are shown in Figures 3 and 4. It can be seen from Figure 3 that the prediction errors for both the driven piles and drilled shafts models are minimal at a learning rate of 0.2. At larger learning rate, the prediction errors increase possibly as a result of the pseudorandom behavior of the optimization algorithm near the local minima in the error surface due to the large step sizes taken in weight space. On the other hand, Figure 4 shows that the performance of the ANN models is relatively insensitive to momentum in the rage between 0.05 to 0.8 , after which the prediction errors increase sharply. The best predictions are obtained at a momentum value of 0.8 for the driven piles model and 0.6 for the drilled shafts model. 


\section{Model validation and robustness}

The performance of the optimum ANN models in the training and validation sets is shown in Figure 5. It can be seen that the ANN models has minimum scatter around the line of equality between the measured and predicted ultimate capacities. The models also have high coefficients of correlation, $r$, in the training or testing sets.

To further examine the generalization ability (robustness) of the ANN models, sensitivity analyses are carried out that demonstrate the response of model predictions to a set of hypothetical input data that lie within the range of the data used for model training. For example, the effect of one input variable, such as pile diameter is investigated by allowing it to change while all other input variables are set to selected constant values. The inputs are then accommodated in the ANN models, and the predicted ultimate pile capacity is calculated. This process is repeated for the next input variable and so on, until the model response has been examined for all inputs. The robustness of the ANN models is determined by examining how well the predictions compare with available geotechnical knowledge and experimental data. The results of the sensitivity analyses for the driven piles and drilled shafts are shown in Figure 6. It can be seen that predictions of ultimate pile capacity from the ANN models agree well with what one would expect and with published experimental results in the sense that the pile capacity increases with the increase of the pile diameter, embedment length, pile tip resistance and pile sleeve resistance. It can also be seen that, within the range of the training data used for ANN driven piles model, concrete piles seem to exhibit higher pile capacity than steel piles which is in agreement with what one would expect as concrete piles provide greater shaft adhesion than steel piles, hence, produce higher pile capacity. 
The above results indicate that the developed ANN models are robust and perform well, thus, can be used with confidence.

\section{Comparison of ANN models with available CPT-based methods}

To examine the accuracy of the driven piles and drilled shafts ANN models against available methods, each ANN model is compared with three CPT-based methods currently used in practice. For driven piles, the ANN model is compared with the European Method (De Ruiter and Beringen 1979), LCPC (Bustamante and Gianeselli 1982) and Eslami and Fellenius (1997). For drilled shafts, the ANN model is compared with methods include Schmertmann (1978), LCPC (Bustamante and Gianeselli 1982) and Alsamman (1995). The comparisons are carried out graphically, as shown in Figures 7 and 8, and analytically using the rank index, $R I$, proposed by Abu-Farsakh and Titi (2004), as given in Table 2. Figures 7 and 8 present the scattering around the line of equality between the predicted and measured pile capacities in relation to the 80 available data records of driven piles and 94 data records of drilled shafts. Obviously better performance is obtained for the method that provides less scattering around the 1:1 line. In addition, better means of visual judgment can be made through the two other dashed lines that indicate $\pm 10 \%$ deviation from the perfect agreement. It can be seen from Figures 7 and 8 that the predictions obtained from the ANN models exhibit less scatter around the line of equality than those obtained from other available methods, especially at higher pile capacity values. The rank index, $R I$, given in Table 2 is calculated as follows (Abu-Farsakh and Titi 2004):

[3]

$$
R I=R_{1}+R_{2}+R_{3}+R_{4}
$$


where; $R_{1}, R_{2}, R_{3}$ and $R_{4}$ are the rank criteria and summarized in the discussion that follows. Optimal performance of a pile capacity prediction method is indicated by a low value of $R I$.

The first criterion, $R_{1}$, is determined by carrying out a regression analysis to obtain the best fit line of predicted versus measured pile capacities in relation to the available 80 case records of driven pile tests and 94 case records of drilled shaft tests. The relationship of the best fit line of $Q_{f i t} / Q_{u}$ and the corresponding coefficient of correlation, $r$, are calculated for each pile capacity prediction method and compared. Based on this criterion, better performance is indicated by the prediction method that has both the ratio $Q_{f i t} / Q_{u}$ and $r$ closer to unity. The results of this criterion are shown in columns 3, 4 and 5 of Table 2 for each of the prediction methods used. For driven piles, Table 2 shows that the ANN model is given $R_{1}=1$ and thus rank first. The ANN model has $Q_{f i t} / Q_{u}=0.98$ with $r=0.97$, which implies that, according to the first criterion, the ANN model tends to under-predict the measured pile capacity by an average of $2 \%$. It can also be seen that two of the remaining driven pile prediction methods (i.e. European method and LCPC) tend to underpredict the measured pile capacity by average values of 10 and $11 \%$, respectively, whereas the method of Eslami and Fellenius tends to over-predict the measured pile capacity by an average of 10\%. On the other hand, Table 2 also shows that, according to the first criterion, the ANN drilled shaft model ranks first as it has $Q_{f i t} / Q_{u}=0.97$ with $r=0.97$, and tends to under-predict the measured pile capacity by an average of $3 \%$. Two of the remaining drilled shaft prediction methods (i.e. Schmertmann and Alsaman) tend to under-predict the measured pile capacity by average values of 9 and $8 \%$, respectively, whereas the LCPC method tends to over-predict the measured pile capacity by an average of $16 \%$. 
The second criterion, $R_{2}$, is obtained by calculating the arithmetic mean value, $\mu$, and the corresponding standard deviation, $\sigma$, of $Q_{p} / Q_{u}$ for the 80 case records of driven piles and 94 case records of drilled shafts. Based on this criterion, optimal performance is obtained when $\mu\left(Q_{p} / Q_{u}\right)$ approaches unity with $\sigma\left(Q_{p} / Q_{u}\right)$ approaching zero. The results of this criterion are given in columns 6,7 and 8 of Table 2, for each of the prediction methods used. For driven piles, it can be seen that, again, the ANN model ranks first with $\mu=1.05$ and $\sigma=0.2$, which means that, according to the second criterion, the ANN method tends to over-predict the measured pile capacity by an average of 5\%. On the other hand, for drilled shafts, the method proposed by Alsamman ranks first with $\mu=1.04$ and $\sigma=0.38$, which means that the method tends to over-predicts the pile capacity by an average value of $4 \%$. The ANN drilled shafts model ranks second in the second criterion as it has $\mu=1.06$ and $\sigma=0.40$, which means that the ANN method tends to over-predict the pile capacity by an average value of $6 \%$.

The third criterion, $R_{3}$, is determined by sorting, in ascending order of $1,2,3, \ldots, i, \ldots, n$, the ratios of $Q_{p} / Q_{u}$ of the 80 driven pile tests and 94 drilled shaft tests for each of the pile capacity prediction methods used against the cumulative probability, $P$, that is calculated according to Long and Wysockey (1999), as follows:

$$
P=\frac{i}{(n+1)}
$$

where; $i=$ order number given for the considered ratio and $n=$ number of pile tests. The $50 \%$ cumulative probability, $P_{50}$, of $Q_{p} / Q_{u}$ is then obtained for each method and used to measure the 
tendency of the prediction methods to over- or under-predict the measured pile capacity. Based on this criterion, optimal performance is indicated by a value of $P_{50}$ approaching unity. The results of this criterion are given in columns 9 and 10 of Table 2. It can be seen that, for driven piles, the ANN model is again ranked first with $P_{50}=1.02$, which means that, according to the third criterion, the ANN method tends to over-predict the measured pile capacity by an average of $2 \%$. On the other hand, the ANN drilled shafts model ranks first with $P_{50}=0.98$, which suggests that, according to the third criterion, the ANN model tends to under-predict the measured pile capacity by an average of $2 \%$.

The fourth criterion, $R_{4}$, is determined by plotting the histogram and lognormal distributions of the ratio $Q_{p} / Q_{u}$ of the 80 driven pile tests and 94 drilled shaft tests for each of the pile capacity prediction methods used. The probability of predicting the pile capacity within $\pm 20 \%$ accuracy is then obtained by calculating the area beneath the histogram and lognormal distributions within a range equal to $0.8 Q_{u} \leq Q_{p} \leq 1.2 Q_{u}$. Based on this criterion, the higher the probability of $\pm 20 \%$ accuracy, the better the performance of the prediction method is. The histogram and lognormal distributions of the methods used are shown in Figure 9 and the corresponding probabilities and rank of the $\pm 20 \%$ accuracy are given in columns 11,12 and 13 of Table 2 . It can be seen from Table 2 that, for driven piles, the ANN model is again ranked first for this criterion with the highest histogram and lognormal distribution probability values of 75 and $70 \%$, respectively. On the other hand, for drilled shafts, Alsamman's method ranks first with histogram and lognormal distribution probabilities of 60 and $56 \%$, respectively. 
The overall rank, as indicated by the rank index, $R I$, of the pile capacity prediction methods used in this work are shown in the last column of Table 2. It can be seen that, the ANN driven piles model has the lowest $R I$ and thus ranks first and performs the best among all driven pile methods used for comparison. It can also be seen that over the four CPT-based methods used, the European method (De Ruiter and Beringen 1979) performs second, followed by the LCPC (Bustamante and Gianeselli 1982) and Eslami and Fellenius (1997). On the other hand, for drilled shafts, the results show that the ANN model and Alsamman's method perform best with similar values of $R I$; however, the ANN model outperforms Alsamman's method as it gives better predictions at high values of pile capacities, as shown previously in the graphical comparison of Figure 8. The results also demonstrate that over the four CPT-based methods used for capacity of drilled shafts, Schmertmann (1978) performs third followed by the LCPC (Bustamante and Gianeselli 1982).

\section{ANN Models for Hand Calculations}

In order to facilitate the use of the developed ANN models, they are translated into simple equations suitable for hand calculations or spreadsheet programming. Details of the weights and biases for the developed ANN models are given in Table 3. For brevity, detailed description of the procedure used to convert the ANN connection weights and biases into simple equations is beyond the scope of this paper and can be found in Shahin et al. (2002b). Based on interpretation of the developed neural network weights and biases, the ultimate capacity of driven piles can be expressed as follows:

$$
Q_{u(A N N)}=290+\left[\frac{4210}{1+e^{\left(-1.699-4.193 \tanh H_{1}+2.242 \tanh H_{2}\right)}}\right]
$$


For steel pile (Material $=1.0)$ :

[6]

$$
H_{1}=-5.1+10^{-3}\left(3.59 D_{e q}+45.51 L+112.23 \bar{q}_{c-t i p}-21.39 \bar{q}_{c-s h a f t}+6.86 \bar{f}_{s}\right)
$$

[7]

$$
H_{2}=1.164-10^{-3}\left(2.47 D_{e q}+33.96 L-8.37 \bar{q}_{c-t i p}+1.58 \bar{q}_{c-s h a f t}-0.24 \bar{f}_{s}\right)
$$

Alternatively, for concrete piles (Material $=2.0$ ):

$[8]$

$$
H_{1}=-5.158+10^{-3}\left(3.59 D_{e q}+45.51 L+112.23 \bar{q}_{c-t i p}-21.39 \bar{q}_{c-s h a f t}+6.86 \bar{f}_{s}\right)
$$

[9]

$$
H_{2}=0.816-10^{-3}\left(2.47 D_{e q}+33.96 L-8.37 \bar{q}_{c-t i p}+1.58 \bar{q}_{c-s h a f t}-0.24 \bar{f}_{s}\right)
$$

where: $Q_{u(A N N)}=$ ultimate pile capacity $(\mathrm{kN}) ; D_{e q}=$ equivalent pile diameter $(\mathrm{mm}) ; L=$ pile embedment length (m); $\bar{q}_{c-t i p}=$ weighted average cone point resistance over pile tip failure zone $(\mathrm{MPa}) ; \bar{q}_{c-s h a f t}=$ weighted average cone point resistance along pile embedment length (MPa); and $\bar{f}_{s}=$ weighted average sleeve friction along pile embedment length $(\mathrm{kPa})$.

On the other hand, the ultimate drilled shafts capacity can be calculated as follows:

[10]

$$
Q_{u(\mathrm{ANN})}=355.8+\left[\frac{9296.3}{1+e^{\left(-1.673-3.364 \tanh H_{1}+4.223 \tanh H_{2}+3.336 \tanh H_{3}\right)}}\right]
$$




$$
H_{1}=-6.509+10^{-3}\left[1.069 D_{\text {stem }}+2.351 D_{\text {base }}-41.152 L-2.174 \bar{q}_{c-\text { base }}+11.271 \bar{q}_{c-\text { shaft }}\right]
$$

$$
H_{2}=0.528+10^{-3}\left[0.553 D_{\text {stem }}+D_{\text {base }}+38.75 L+1.59 \bar{q}_{c-b a s e}+5.344 \bar{q}_{c-s h a f t}\right]
$$

$$
H_{3}=3.777-10^{-3}\left[0.772 D_{\text {stem }}-0.537 D_{\text {base }}+83.37 L+23.31 \bar{q}_{c-\text { base }}+56.23 \bar{q}_{c-\text { shaft }}\right]
$$

where; $Q_{u(A N N)}=$ ultimate drilled shaft capacity $(\mathrm{kN}), D_{\text {stem }}=$ shaft stem diameter $(\mathrm{mm}), D_{\text {base }}=$ shaft base diameter $(\mathrm{mm}), L=$ shaft embedment length $(\mathrm{m}), \bar{q}_{c-b a s e}=$ weighted average cone point resistance over shaft base failure zone $(\mathrm{MPa})$ and $\bar{q}_{c-\text { shaft }}=$ weighted average cone tip resistance along shaft embedment length (MPa).

\section{Illustrative numerical example}

An illustrative numerical example is provided to better explain the implementation of the developed pile capacity design formula. A driven pile with a diameter of $300 \mathrm{~mm}$ is embedded into the ground to a depth of $15 \mathrm{~m}$. The soil has a weighted average cone point resistance of $5 \mathrm{MPa}$ over the pile tip failure zone and $6 \mathrm{MPa}$ along the pile length. The weighted average sleeve friction along the pile length is $40 \mathrm{kPa}$. The ultimate pile capacity is required for both steel and concrete piles.

\section{Solution:}

Given the information provided, $D_{e q}=300 \mathrm{~mm} ; L=15 \mathrm{~m} ; \bar{q}_{c-t i p}=5 \mathrm{MPa} ; \bar{q}_{c-s h a f t}=6 \mathrm{MPa}$; and $\bar{f}_{s}=$ $40 \mathrm{kPa}$. 
(a) For steel piles, Eqs. (6) and (7), respectively, are applied as follows:

$$
\begin{aligned}
& H_{1}=-5.1+10^{-3}(3.59 \times 300+45.51 \times 15+112.23 \times 5-21.39 \times 6+6.86 \times 40)=-2.63314 \\
& H_{2}=1.164-10^{-3}(2.47 \times 300+33.96 \times 15-8.37 \times 5+1.58 \times 6-0.24 \times 40)=-0.04443
\end{aligned}
$$

By substituting $H_{1}$ and $H_{2}$ into Eq. (5), the predicted pile capacity can be obtained as follows:

$$
Q_{u(A N N)}=290+\left[\frac{4210}{1+e^{(-1.699-4.193 \tanh (-2.63314)+2.242(-0.04443)}}\right]=656.1 \mathrm{kN}
$$

(b) For concrete piles, Eqs. (8) and (9), respectively, are applied as follows:

$$
\begin{aligned}
& H_{1}=-5.158+10^{-3}(3.59 \times 300+45.51 \times 15+112.23 \times 5-21.39 \times 6+6.86 \times 40)=-2.69114 \\
& H_{2}=0.816-10^{-3}(2.47 \times 300+33.96 \times 15-8.37 \times 5+1.58 \times 6-0.24 \times 40)=-0.39243
\end{aligned}
$$

By substituting $H_{1}$ and $H_{2}$ into Eq. (5), the predicted pile capacity can be obtained as follows:

$$
Q_{u(A N N)}=290+\left[\frac{4210}{1+e^{(-1.699-4.193 \tanh (-2.69114)+2.242(-0.39243)}}\right]=986.5 \mathrm{kN}
$$

Hence, in this example, the steel driven pile results in $33 \%$ lower ultimate pile capacity than the concrete pile. Eqs. (10) to (13) can be similarly used for predicting axial capacity of drilled shafts.

\section{Summary and Conclusions}

The work presented in this paper has used a series of in-situ pile load tests collected from the literature to develop artificial neural networks (ANNs) based models for pile capacity predictions of driven piles and drilled shafts. The predictive ability of the ANN models was examined by comparing their predictions with those obtained from experiments. Sensitivity analyses were carried out on the ANN models to explore their generalization ability (robustness). 
The performance of the ANN models was further investigated against the most commonly used CPT-based pile capacity prediction methods. Comprehensive statistical analyses using the rank index, $R I$, were conducted to rank and evaluate the performance of the ANN models and CPT methods. $R I$ compares the actual measured pile capacity, $Q_{u}$, with the corresponding predicted pile capacity, $Q_{p}$, from the prediction methods used, and comprises four statistical criteria, including the best-fit of $Q_{p}$ versus $Q_{u}$, the arithmetic mean and standard deviation of $Q_{p} / Q_{u}$, the $50 \%$ cumulative probability of $Q_{p} / Q_{u}$ and the \pm 20 accuracy of the histogram and lognormal distribution curves of $Q_{p} / Q_{u}$. Finally, tractable design formulas based on the ANN models were derived to facilitate the use of the models for routine design practice by hand calculations.

The results indicate that the ANN models were capable of accurately predicting the ultimate capacity of pile foundations with high coefficients of correlation, $r$. For driven piles, the ANN model had $r$ of 0.96 and 0.85 in the calibration and validation sets, respectively, whereas the ANN drilled shafts model had $r$ of 0.97 in both the calibration and validation sets. The sensitivity analyses carried out on both the driven piles and drilled shafts ANN models indicate that predictions from the ANN models compare well with what one would expect based on available geotechnical knowledge and experimental results. The results of the rank index, $R I$, yielded the following overall rank for the CPT-based methods of driven pile capacity predictions: 1 , the ANN model (this study); 2, Eslami and Fellenius (1997); 3, LCPC (Bustamante and Gianeselli 1982); 4, the European method (De Ruiter and Beringen 1979) . On the other hand, for drilled shafts, the results of $R I$ showed equal overall rank for the ANN model and the method proposed by Alsamman (1995), followed by the Schmertmann method (1978) and the LCPC (Bustamante and Gianeselli 1982). 
It is worthwhile noting that predictions from ANN models are better when used for ranges of input variables similar to those utilized in model training. This is because ANNs work well for interpolation rather than extrapolation. However, the ranges of input variables used in the current work represent those values that are usually used in practice. It is recommended though that in the future the developed ANNs be updated to obtain better predictions by presenting new training examples of wider ranges, as new data become available. 


\section{References}

Abu-Farsakh, M.Y., and Titi, H.H. 2004. Assessment of direct cone penetration test methods for predicting the ultimate capacity of friction driven piles. Journal of Geotechnical and Geoenvironmental Engineering, 130(9): 935-944.

Abu-Kiefa, M.A. 1998. General regression neural networks for driven piles in cohesionless soils. Journal of Geotechnical \& Geoenvironmental Engineering, 124(12): 1177-1185.

Alsamman, O.M. 1995. The use of CPT for calculating axial capacity of drilled shafts. PhD Thesis, University of Illinois-Champaign, Urbana, Illinois.

Briaud, J.L., and Miran, J. 1992. The cone penetrometer test, Report FHWA-SA-91-043, U. S. Department of Transportation.

Brinch Hansen, J. 1963. Discussion on hyperbolic stress-strain response, cohesive soils. Journal of Soil Mechanics and Foundation Engineering, 89(SM4): 241-242.

Bustamante, M., and Gianeselli, L. 1982. Pile bearing capacity prediction by means of static penetrometer CPT. In Proceedings of the 2nd European Symposium on Penetration Testing. Amsterdam, Vol.2, pp. 493-500.

Caudill, M. 1988. Neural networks primer, Part III. AI Expert, 3(6): 53-59.

De Ruiter, J., and Beringen, F.L. 1979. Pile foundation for large North Sea structures. Marine Geotechnology, 3(3): 267-314.

Eslami, A. 1996. Bearing capacity of piles from cone penetration test data. $\mathrm{PhD}$ Thesis, University of Ottawa, Ottawa, Ontario.

Eslami, A., and Fellenius, B.H. 1997. Pile capacity by direct CPT and CPTu methods applied to 102 case histories. Canadian Geotechnical Journal, 34(6): 886-904.

Fausett, L.V. 1994. Fundamentals neural networks: Architecture, algorithms, and applications. Prentice-Hall, Englewood Cliffs, New Jersey.

Hornik, K., Stinchcombe, M., and White, H. 1989. Multilayer feedforward networks are universal approximators. Neural Networks, 2: 359-366.

Kulhawy, F.H., and Mayne, P.W. 1990. Manual on estimating soil properties for foundation design Report Report EL-6800, Electric Power Research Institute, Palo Alto, CA.

Lee, I.M., and Lee, J.H. 1996. Prediction of pile bearing capacity using artificial neural networks. Computers and Geotechnics, 18(3): 189-200. 
Long, J.H., and Wysockey, M.H. 1999. Accuracy of methods for predicting axial capacity of deep foundations. In Proceedings of the OTRC '99 Conference: Analysis, Design, Construction, and Testing of Deep Foundations. Reston, VA. ASCE, Vol.GSP NO. 88, pp. 190-195.

Masters, T. 1993. Practical neural network recipes in C++. Academic Press, San Diego, California.

Neusciences 2000. Neuframe Version 4.0. Neusciences Corp., Southampton, Hampshire.

Reese, L.C., and O'Neill, M.W. 1988. Drilled shafts: Construction procedures and design methods, Report FHWA-HI-88-042, U. S. Department of Transportation, Dallas, Texas.

Rumelhart, D.E., Hinton, G.E., and Williams, R.J. 1986. Learning internal representation by error propagation. In Parallel Distributed Processing. MIT Press, Cambridge.

Schmertmann, J.H. 1978. Guidelines for cone penetration test, performance and design, Report Report No. FHWA-TS-78-209, U. S. Department of Transportation, Washington, D. C.

Shahin, M.A. 2008. Modelling axial capacity of pile foundations by intelligent computing. In Proceedings of the Second BGA International Conference on Foundations, ICOF2008. Dundee, Scotland. IHS BRE Press, pp. 283-294.

Shahin, M.A., and Jaksa, M.B. 2006. Pullout capacity of small ground anchors by direct cone penetration test methods and neural networks. Canadian Geotechnical Journal, 43(6): 626637.

Shahin, M.A., and Indraratna, B. 2006. Modelling the mechanical behaviour of railway ballast using artificial neural networks. Canadian Geotechnical Journal, 43(1): 1144-1152.

Shahin, M.A., Jaksa, M.B., and Maier, H.R. 2001. Artificial neural network applications in geotechnical engineering. Australian Geomechanics, 36(1): 49-62.

Shahin, M.A., Maier, H.R., and Jaksa, M.B. 2002a. Predicting settlement of shallow foundations using neural networks. Journal of Geotechnical \& Geoenvironmental Engineering, 128(9): 785-793.

Shahin, M.A., Jaksa, M.B., and Maier, H.R. 2002b. Artificial neural network-based settlement prediction formula for shallow foundations on granular soils. Australian Geomechanics, 37(4): 45-52.

Shahin, M.A., Maier, H.R., and Jaksa, M.B. 2004. Data division for developing neural networks applied to geotechnical engineering. Journal of Computing in Civil Engineering, 18(2): 105114. 
Shahin, M.A., Jaksa, M.B., and Maier, H.R. 2009. Recent advances and future challenges for artificial neural systems in geotechncial engineering applications. Journal of Advances in Artificial Neural Systems: in review. 


\section{Figure Captions:}

Fig. 1: Typical structure and operation of ANNs

Fig. 2. Effect of number of hidden layer nodes on performance of ANN models

Fig. 3. Effect of learning rate on performance of ANN models

Fig. 4. Effect of momentum term on performance of ANN models

Fig. 5. Performance of ANN models in the training and validations sets

Fig. 6. Sensitivity analyses to test the robustness of ANN models

Fig. 7. Performance of the ANN driven piles model compared to other CPT-based methods

Fig. 8. Performance of the ANN drilled shafts model compared to other CPT-based methods

Fig. 9. Histograms and lognormal distributions of $Q_{p} / Q_{u}$ of the ANN models and other CPT-based methods 
Fig. 1
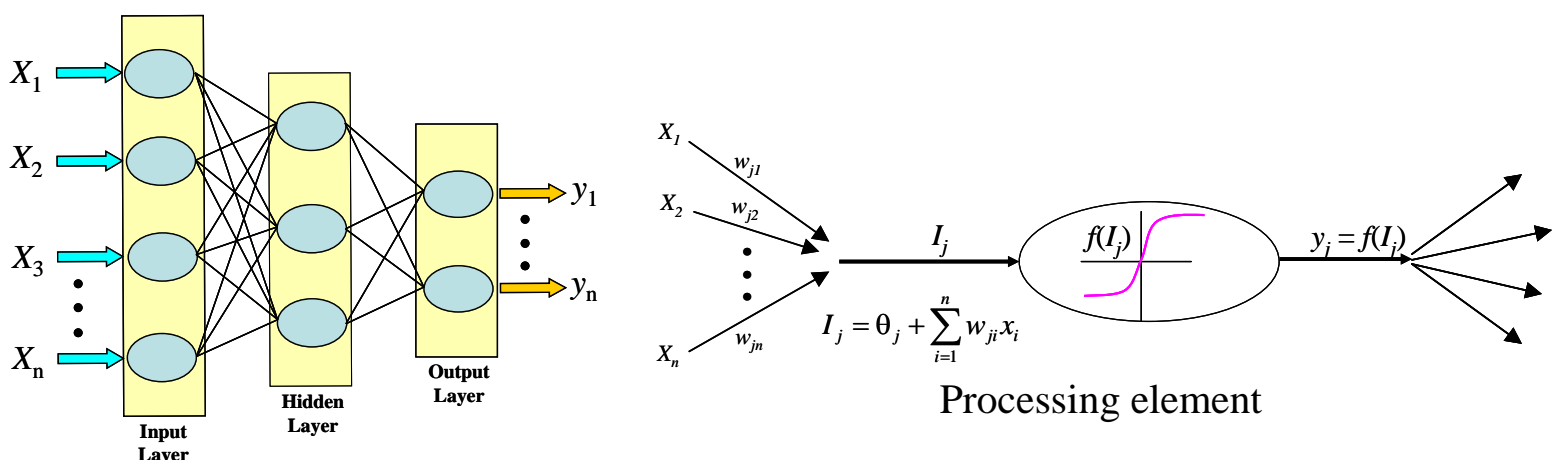

Artificial neural network 
Fig. 2

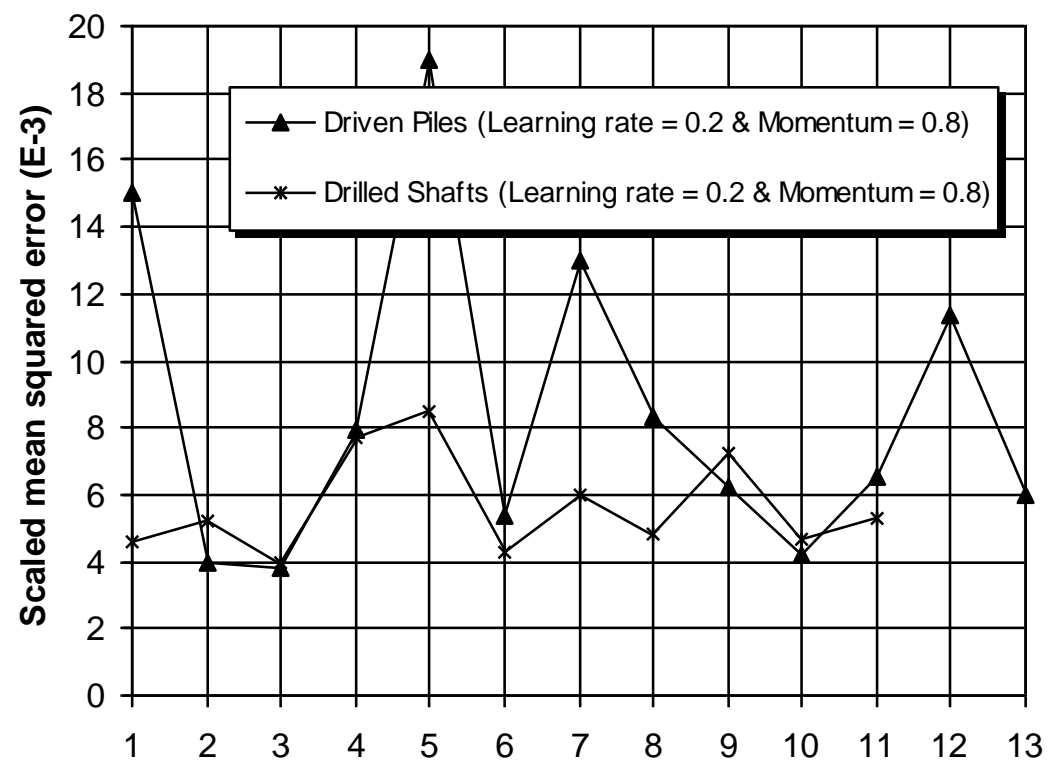

No. hidden nodes 
Fig. 3

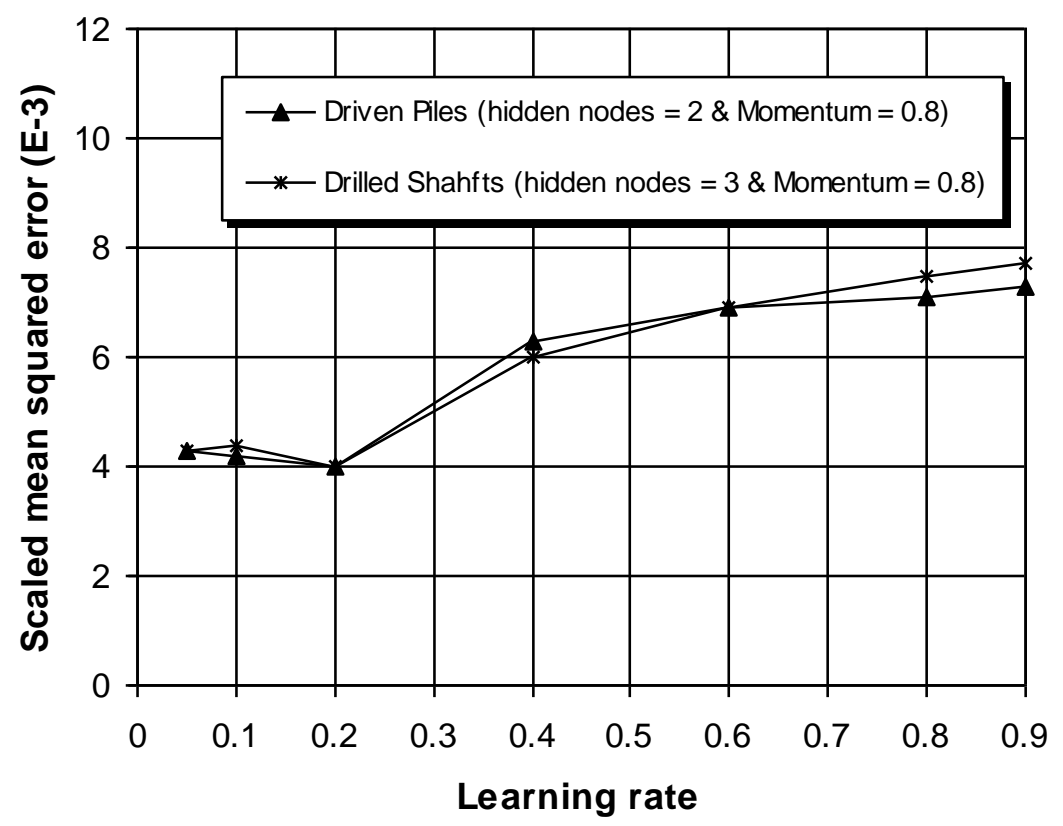


Fig. 4

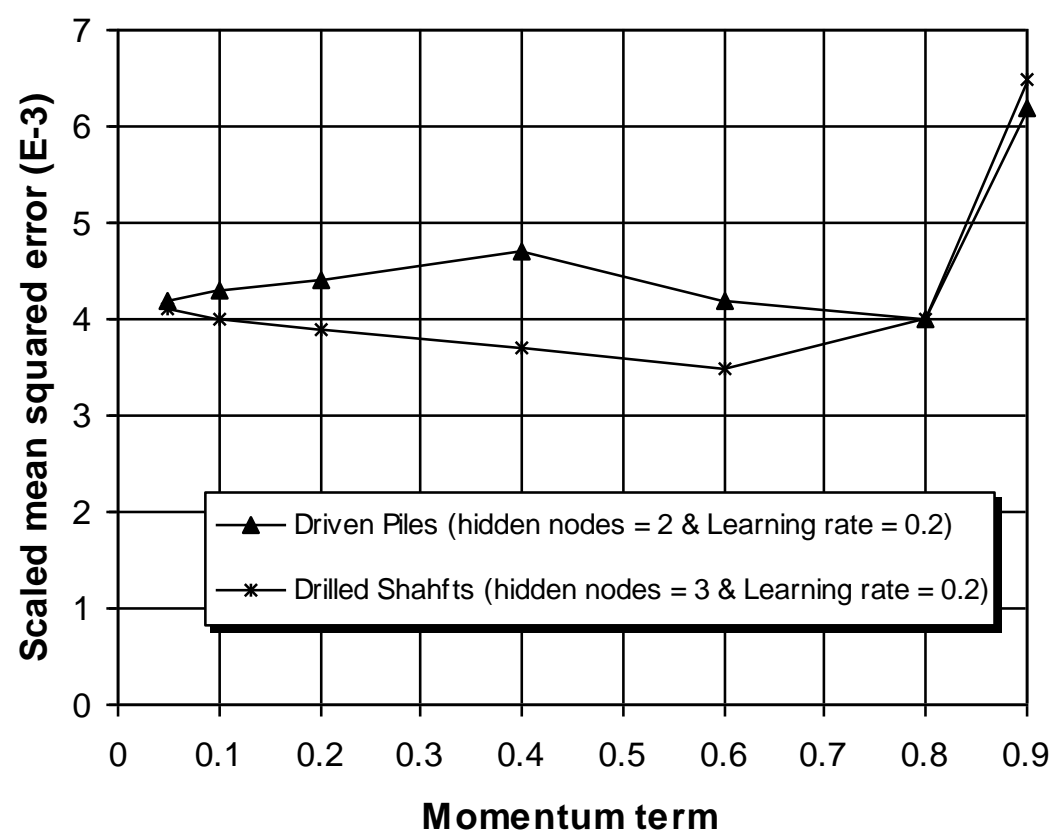


Fig. 5

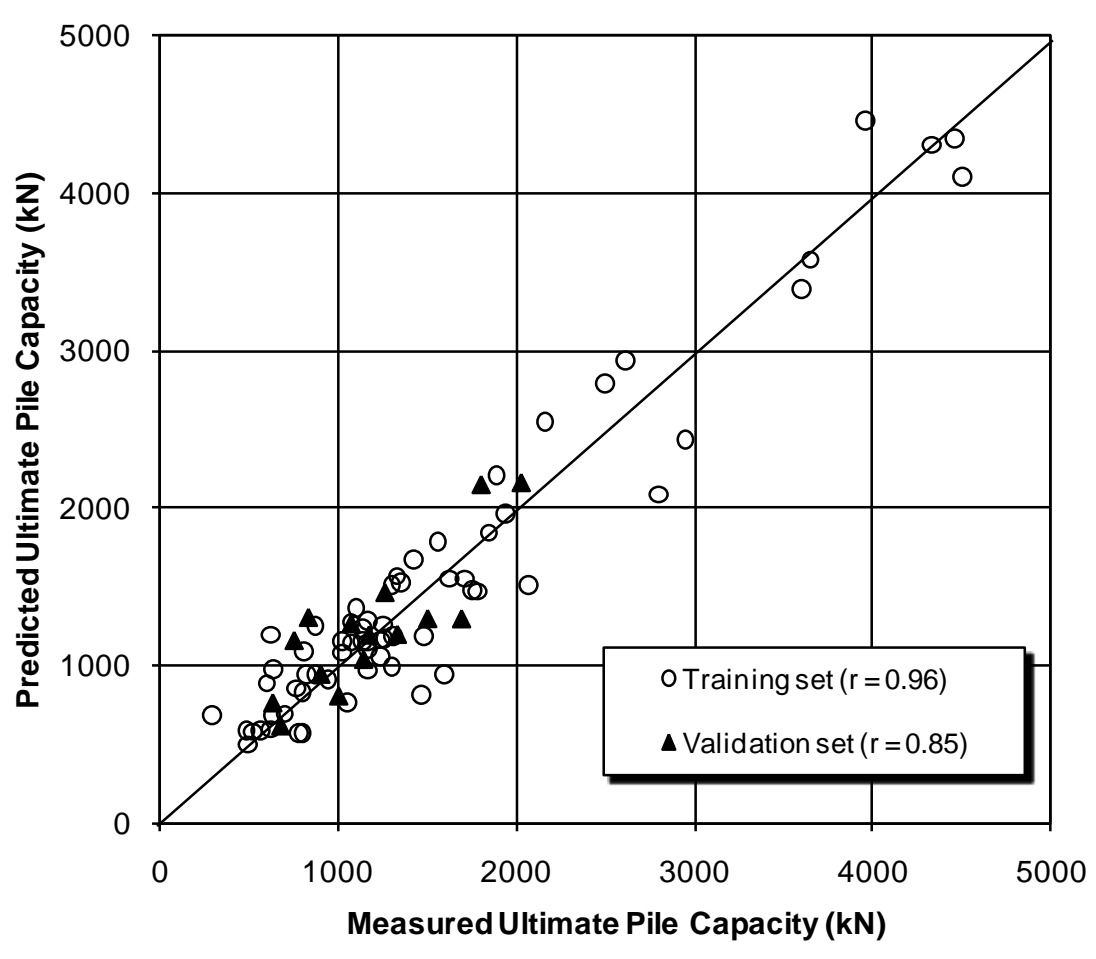

(a) Driven piles model

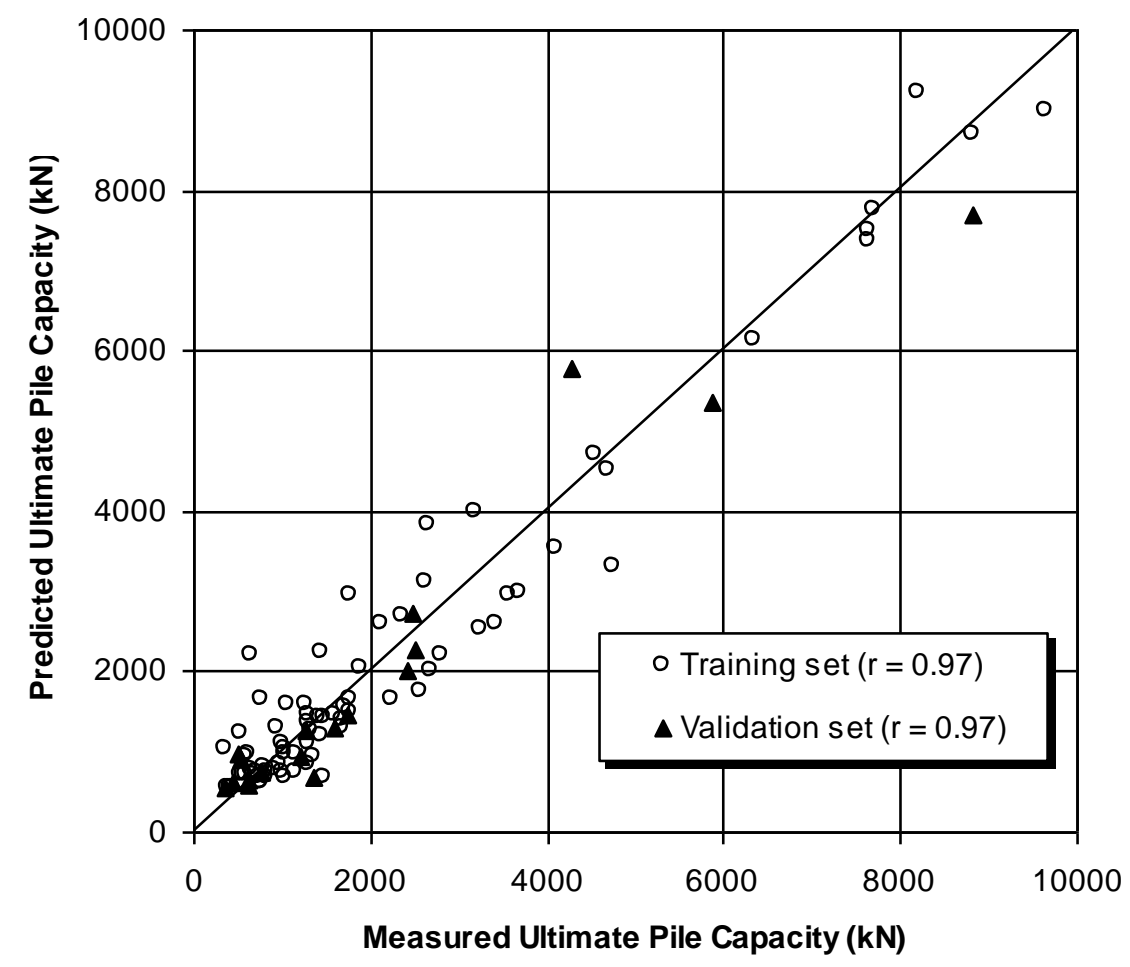

(b) Drilled shafts model 
Fig. 6
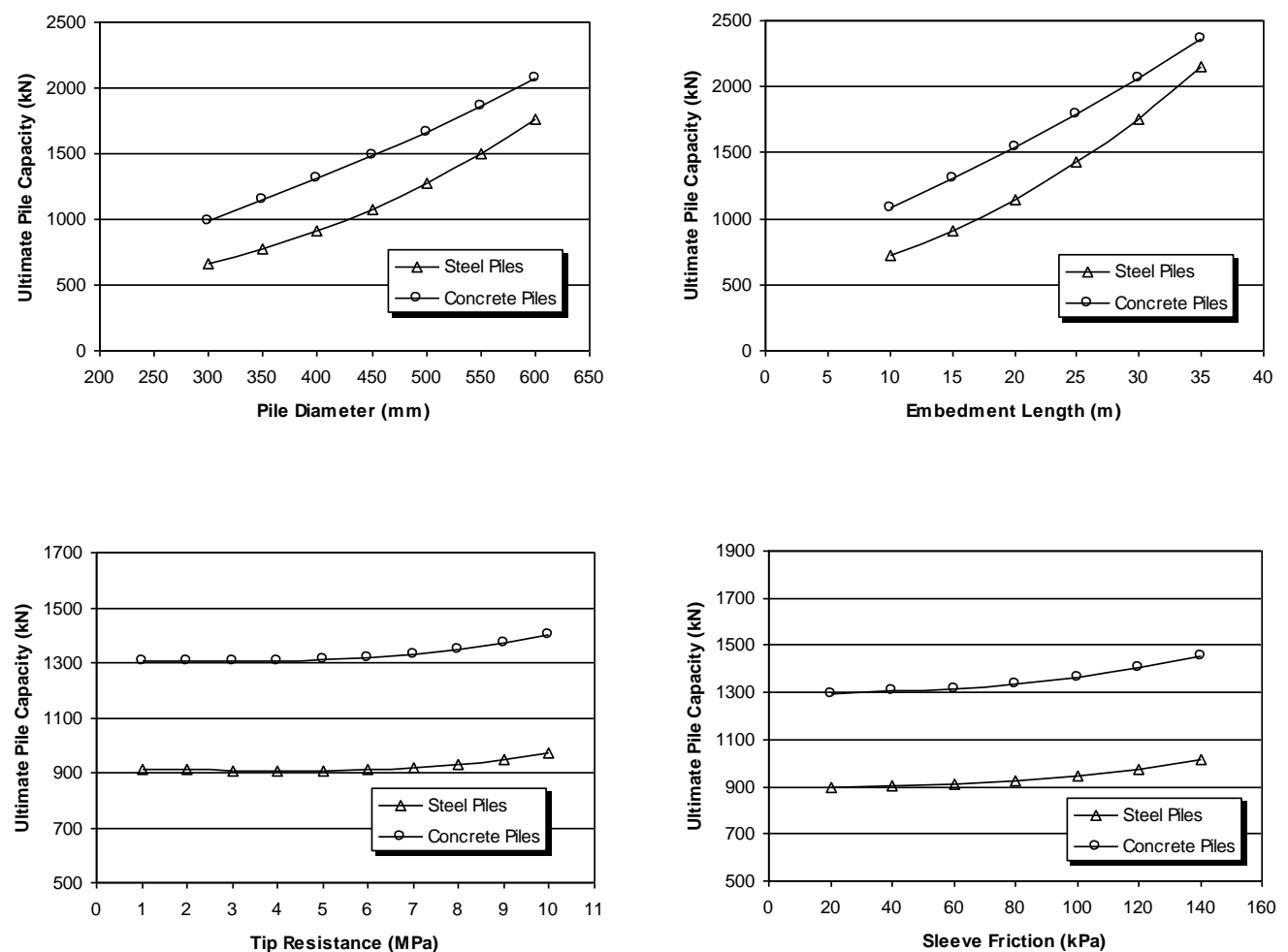

(a) Driven piles model
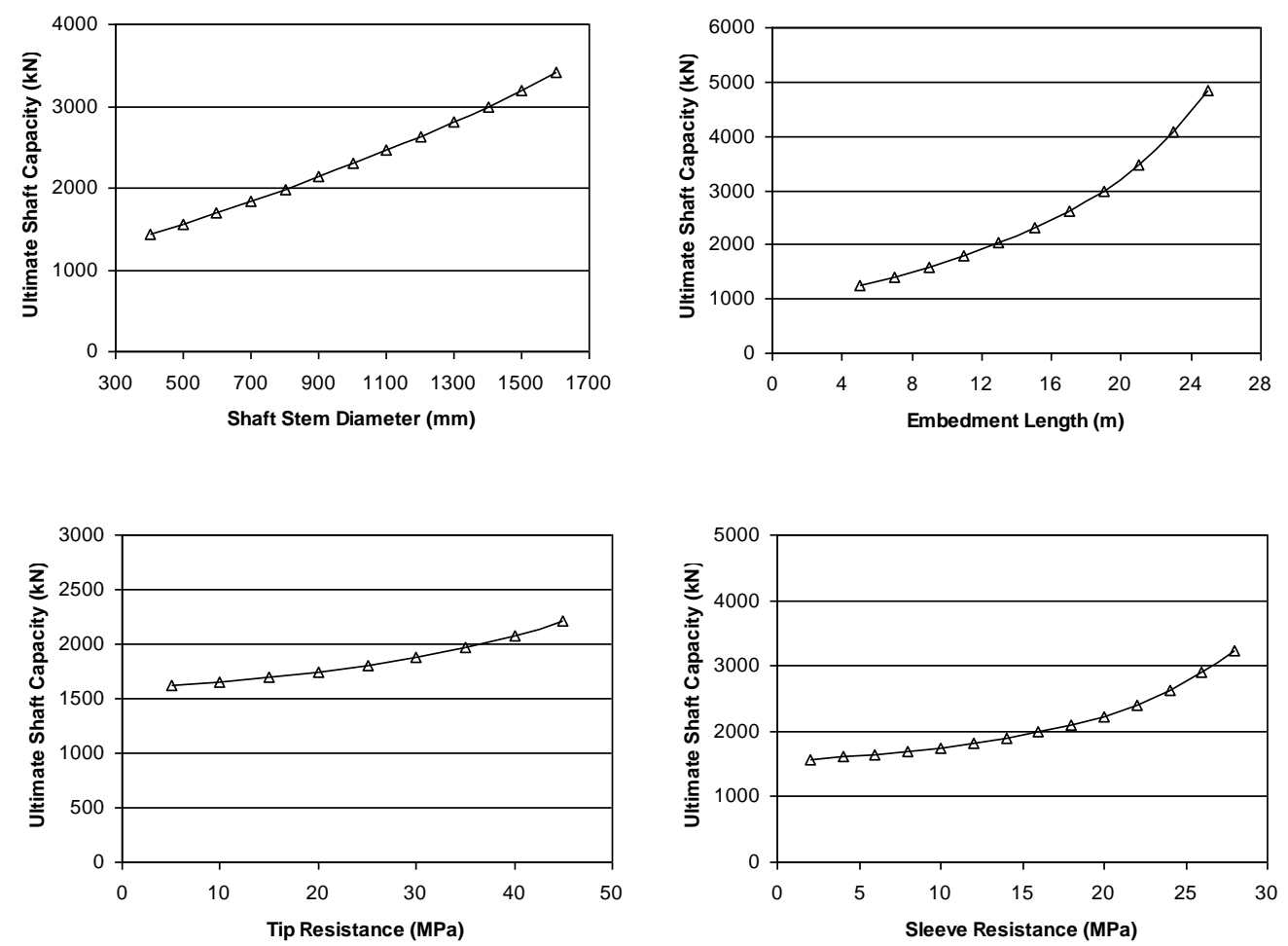

(b) Drilled shafts model 
Fig. 7
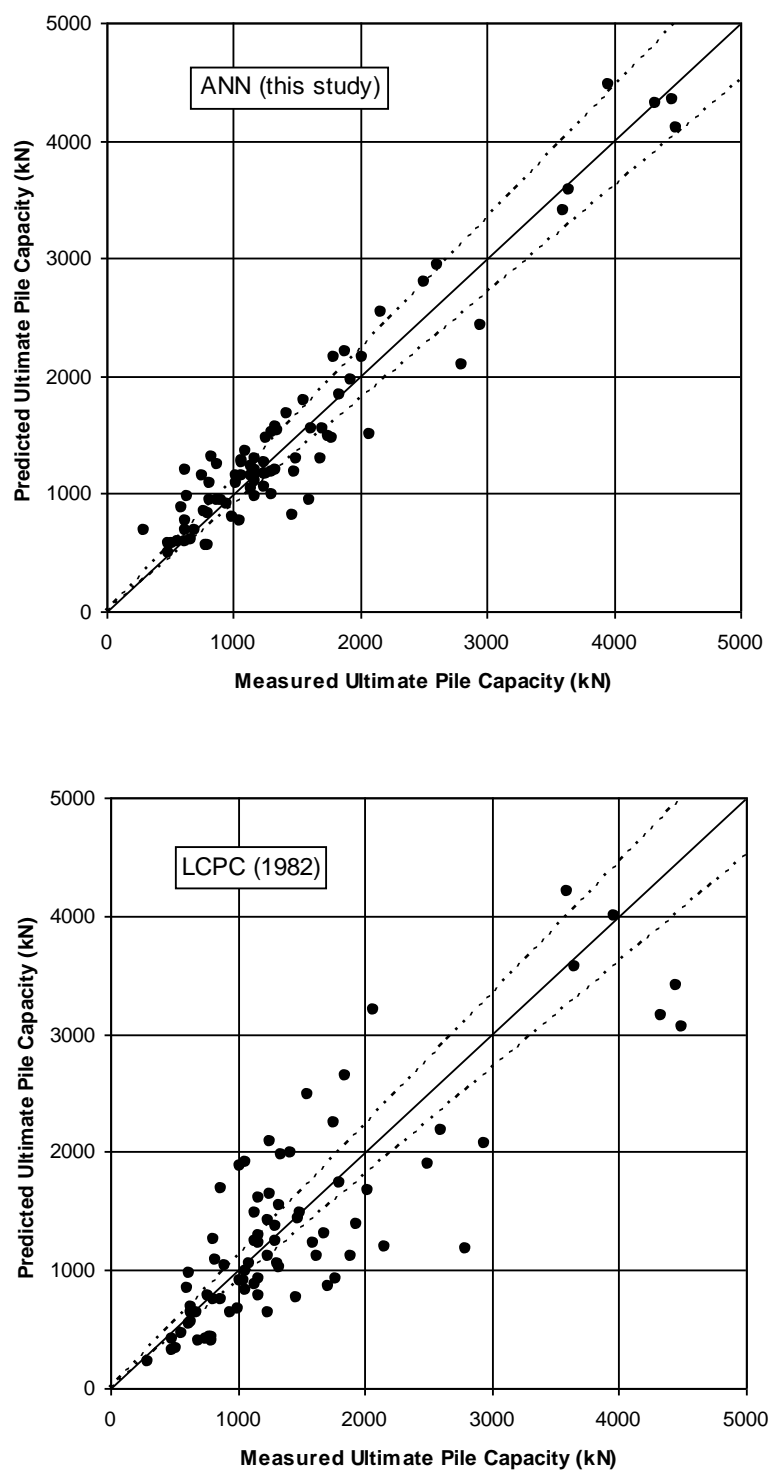
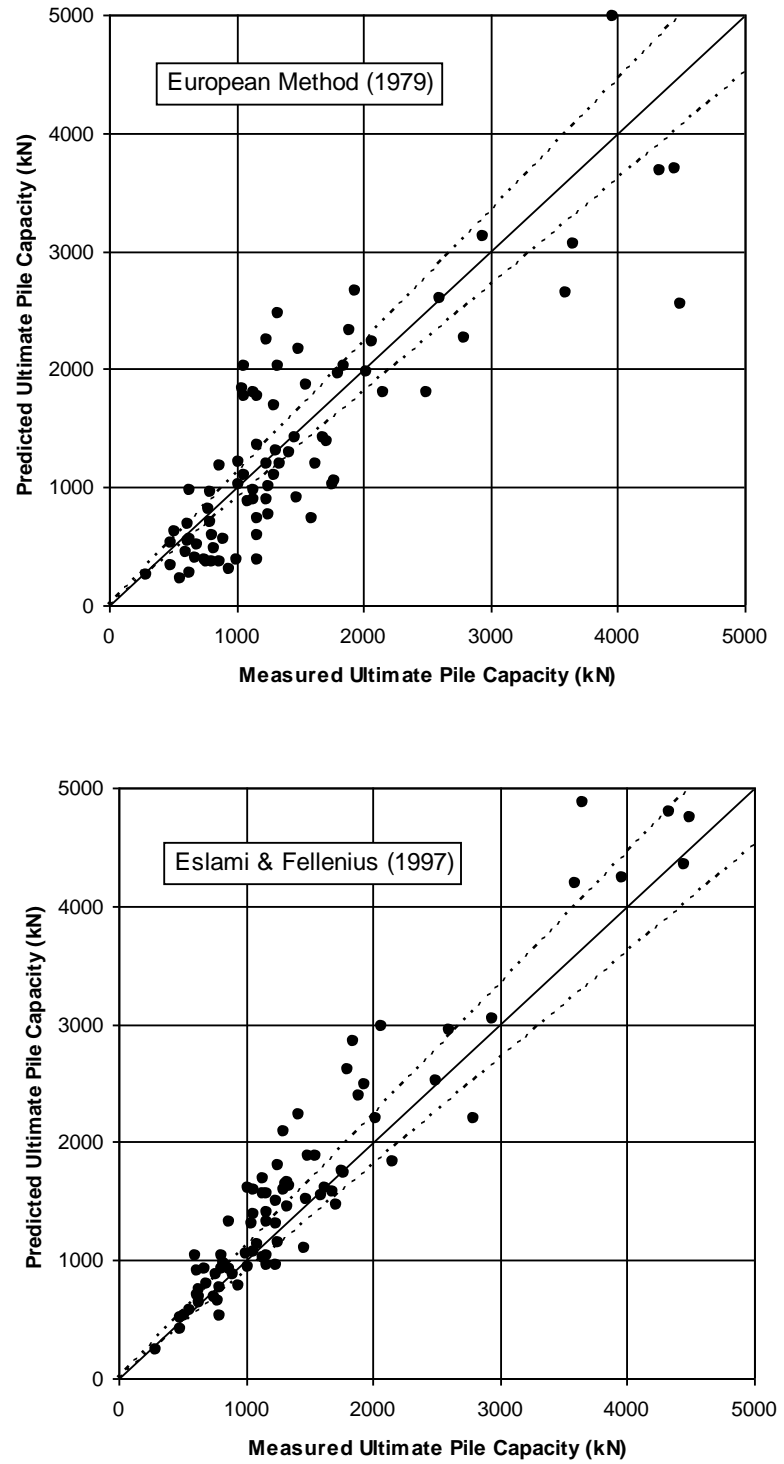
Fig. 8
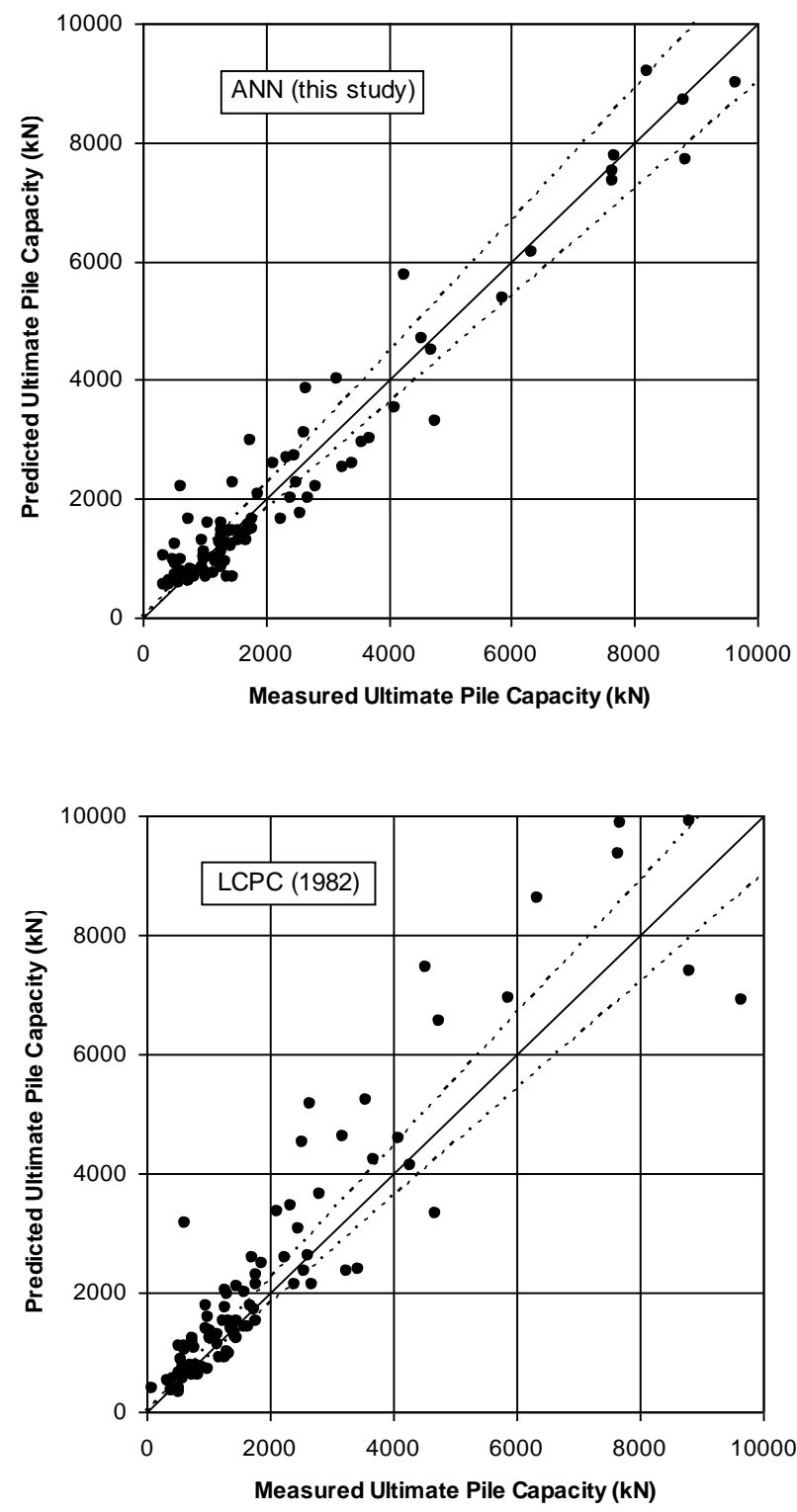
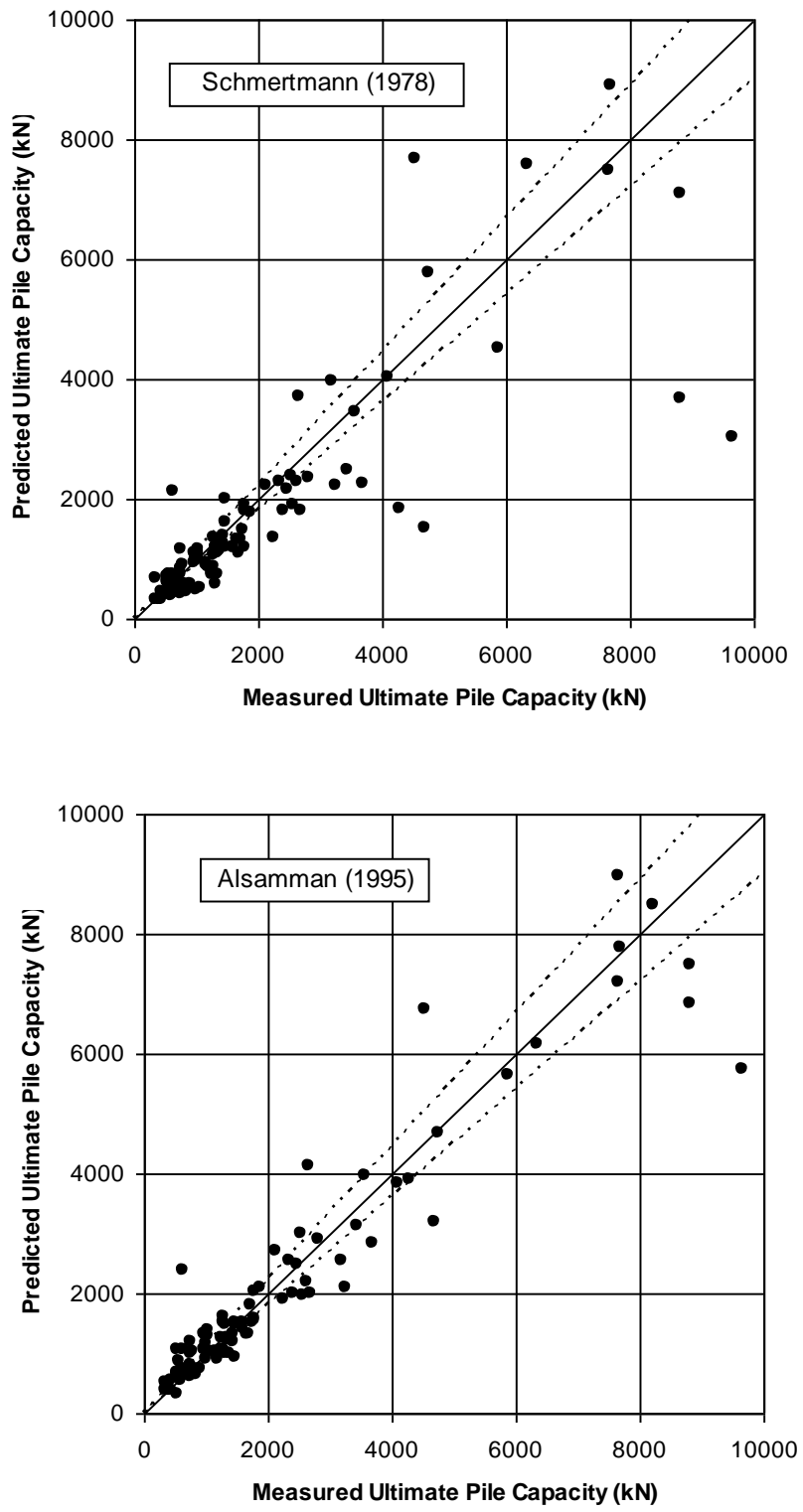
Fig. 9
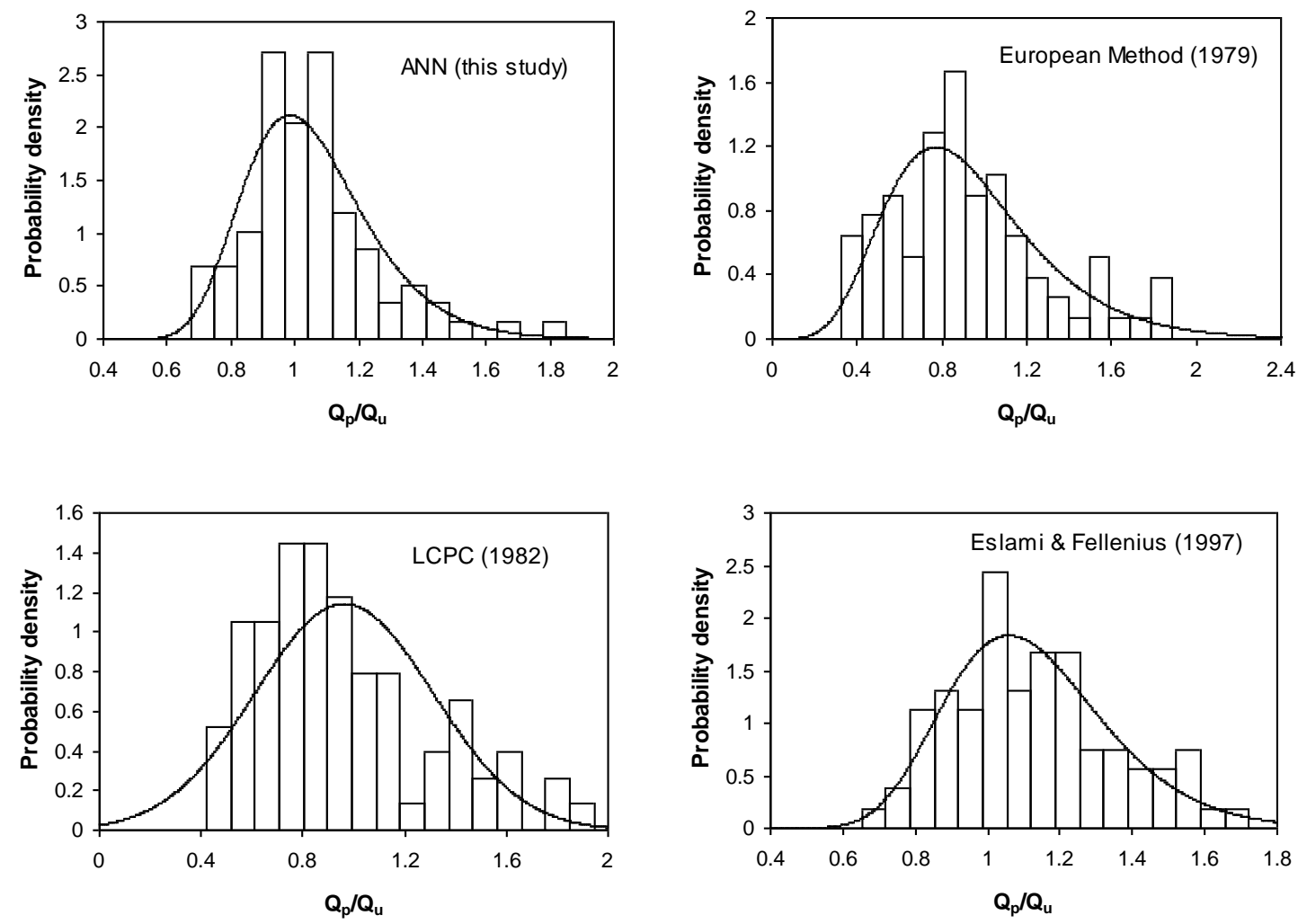

(a) Driven piles
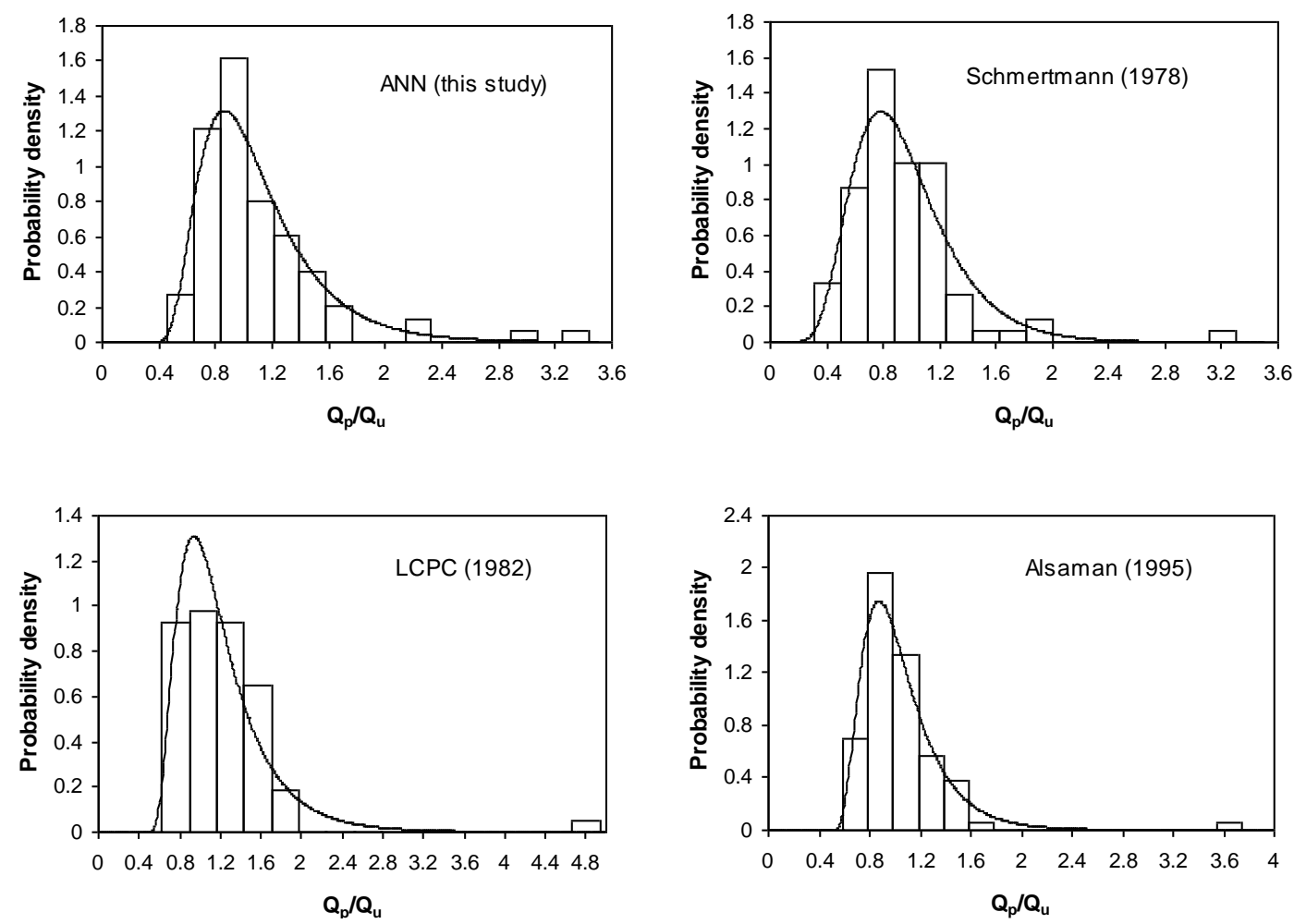

(b) Drilled shafts 
Table 1. ANN input and output statistics

\begin{tabular}{|c|c|c|c|c|c|c|}
\hline \multirow[t]{2}{*}{ Pile type } & \multirow{2}{*}{$\begin{array}{l}\text { Input/output variables } \\
\text { and data sets }\end{array}$} & \multicolumn{5}{|c|}{ Statistical parameters } \\
\hline & & Mean & $\begin{array}{l}\text { Standard } \\
\text { deviation }\end{array}$ & Minimum & Maximum & Range \\
\hline \multirow[t]{18}{*}{ Driven piles } & \multicolumn{6}{|c|}{ Pile equivalent diameter, $D_{e q}(\mathrm{~mm})$} \\
\hline & Training set & 412.3 & 127.0 & 250.0 & 900.0 & 650.0 \\
\hline & Validation set & 395.5 & 85.5 & 273.0 & 600.0 & 337.0 \\
\hline & \multicolumn{6}{|c|}{ Pile embedment length, $L(\mathrm{~m})$} \\
\hline & Training set & 17.2 & 9.1 & 5.5 & 41.8 & 36.3 \\
\hline & Validation set & 13.9 & 6.3 & 7.6 & 31.4 & 23.8 \\
\hline & \multicolumn{6}{|c|}{ Weighted average cone point resistance over pile tip failure zone, $\bar{q}_{c-t i p}(\mathrm{MPa})$} \\
\hline & Training set & 5.2 & 4.7 & 0.0 & 20.0 & 20.0 \\
\hline & Validation set & 4.9 & 4.6 & 0.0 & 19.5 & 19.5 \\
\hline & \multicolumn{6}{|c|}{ Weighted average cone point resistance over pile length, $\bar{q}_{c-\text { shaft }}(\mathrm{MPa})$} \\
\hline & Training set & 6.4 & 4.8 & 1.4 & 18.3 & 16.9 \\
\hline & Validation set & 4.9 & 3.8 & 2.0 & 16.5 & 14.5 \\
\hline & \multicolumn{6}{|c|}{ Weighted average sleeve friction over pile length, $\bar{f}_{s}(\mathrm{kPa})$} \\
\hline & Training set & 55.6 & 30.4 & 10.0 & 174.0 & 164.0 \\
\hline & Validation set & 57.3 & 36.5 & 20.0 & 160.0 & 140.0 \\
\hline & \multicolumn{6}{|c|}{ Ultimate capacity, $Q_{u}(\mathrm{kN})$} \\
\hline & Training set & 1509.9 & 1004.3 & 290.0 & 4500.0 & 4210.0 \\
\hline & Validation set & 1184.7 & 420.8 & 630.0 & 2025.0 & 1395.0 \\
\hline \multirow[t]{18}{*}{ Drilled shafts } & \multicolumn{6}{|c|}{ Shaft stem diameter, $D_{\text {stem }}(\mathrm{mm})$} \\
\hline & Training set & 617.0 & 371.9 & 304.8 & 1798.3 & 1493.5 \\
\hline & Validation set & 525.8 & 245.5 & 320.0 & 1100.3 & 780.3 \\
\hline & \multicolumn{6}{|c|}{ Shaft base diameter, $D_{\text {base }}(\mathrm{mm})$} \\
\hline & Training set & 741.7 & 417.9 & 304.8 & 2100.1 & 1795.3 \\
\hline & Validation set & 630.6 & 277.5 & 320.0 & 1149.1 & 829.1 \\
\hline & \multicolumn{6}{|c|}{ Shaft embedment length, $L(\mathrm{~m})$} \\
\hline & Training set & 10.0 & 4.7 & 4.5 & 27.4 & 22.9 \\
\hline & Validation set & 9.0 & 4.4 & 5.8 & 24.2 & 18.3 \\
\hline & \multicolumn{6}{|c|}{ Weighted average cone point resistance along base failure zone, $\bar{q}_{c-b a s e}(\mathrm{MPa})$} \\
\hline & Training set & 16.8 & 10.3 & 0.0 & 47.5 & 47.5 \\
\hline & Validation set & 18.2 & 11.7 & 0.0 & 39.5 & 39.5 \\
\hline & \multicolumn{6}{|c|}{ Weighted average cone point resistance along shaft length, $\bar{q}_{c-\text { shaft }}(\mathrm{MPa})$} \\
\hline & Training set & 8.2 & 5.2 & 1.1 & 28.8 & 27.7 \\
\hline & Validation set & 10.1 & 5.3 & 2.5 & 21.5 & 19.0 \\
\hline & \multicolumn{6}{|c|}{ Ultimate capacity, $Q_{u}(\mathrm{kN})$} \\
\hline & Training set & 2184.3 & 2161.5 & 355.8 & 9652.2 & 9296.3 \\
\hline & Validation set & 2075.0 & 2221.9 & 355.8 & 8824.8 & 8468.9 \\
\hline
\end{tabular}


Table 2. Performance of ANN models against available CPT-based methods

\begin{tabular}{|c|c|c|c|c|c|c|c|c|c|c|c|c|c|}
\hline \multirow[t]{2}{*}{$\begin{array}{l}\text { Pile } \\
\text { type }\end{array}$} & \multirow[t]{2}{*}{ Method } & \multicolumn{3}{|c|}{ Best fit calculations } & \multicolumn{3}{|c|}{ Arithmetic calculations } & \multicolumn{2}{|c|}{$\begin{array}{l}\text { Cumulative } \\
\text { probability }\end{array}$} & \multicolumn{3}{|c|}{ Accuracy $\pm 20 \%$} & \multirow{2}{*}{$\begin{array}{l}\text { Overall } \\
\text { rank } \\
R I\end{array}$} \\
\hline & & $Q_{f i t} / Q_{u}$ & $r$ & $R_{1}$ & $\mu\left(Q_{p} / Q_{u}\right)$ & $\sigma\left(Q_{p} / Q_{u}\right)$ & $\boldsymbol{R}_{2}$ & $P_{50}$ & $\boldsymbol{R}_{3}$ & Histogram & Lognormal & $\boldsymbol{R}_{4}$ & \\
\hline \multirow{4}{*}{$\begin{array}{l}\text { Driven } \\
\text { piles }\end{array}$} & ANN (this study) & 0.98 & 0.97 & 1 & 1.05 & 0.20 & 1 & 1.02 & 1 & 75 & 70 & 1 & 4 \\
\hline & European method (1979) & 0.90 & 0.85 & 3 & 0.93 & 0.37 & 3 & 0.86 & 4 & 38 & 42 & 4 & 14 \\
\hline & LCPC (1982) & 0.89 & 0.83 & 4 & 0.96 & 0.35 & 2 & 0.88 & 3 & 40 & 43 & 3 & 12 \\
\hline & Eslami \& Fellenius (1997) & 1.10 & 0.95 & 2 & 1.13 & 0.23 & 4 & 1.09 & 2 & 59 & 61 & 2 & 10 \\
\hline \multirow{4}{*}{$\begin{array}{l}\text { Drilled } \\
\text { shafts }\end{array}$} & ANN (this study) & 0.97 & 0.97 & 1 & 1.06 & 0.40 & 2 & 0.98 & 1 & 51 & 45 & 2 & 6 \\
\hline & Schmertmann (1978) & 0.91 & 0.83 & 3 & 0.93 & 0.40 & 3 & 0.86 & 3 & 49 & 41 & 3 & 11 \\
\hline & LCPC (1982) & 1.16 & 0.93 & 4 & 1.19 & 0.51 & 4 & 1.14 & 4 & 47 & 39 & 4 & 16 \\
\hline & Alsamman (1995) & 0.92 & 0.95 & 2 & 1.04 & 0.38 & 1 & 0.96 & 2 & 60 & 56 & 1 & 6 \\
\hline
\end{tabular}

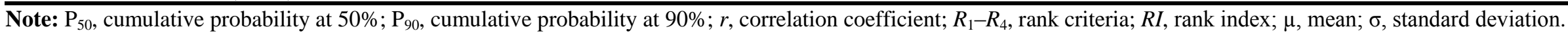


Table 3. Weights and biases of the developed ANN models

Driven piles model has 3 layers:

Input layer has six nodes (Nodes \# 1 to 6)

Hidden layer has two nodes (Nodes \# 7 and 8)

Output layer has one node (Node \# 9)

\begin{tabular}{|c|c|c|c|c|c|c|}
\hline \multicolumn{7}{|c|}{ Weights from input layer to hidden layer } \\
\hline Node \# & 1 & 2 & 3 & 4 & 5 & 6 \\
\hline 7 & 2.3323 & 1.6521 & 2.2446 & -0.3615 & 1.1252 & -0.0577 \\
\hline 8 & -1.6083 & -1.2328 & 0.167473 & -0.0266 & 0.0387 & -0.3481 \\
\hline \multicolumn{7}{|c|}{ Weights from hidden layer to output layer } \\
\hline Node \# & 7 & 8 & & & & \\
\hline 9 & 4.1934 & -2.2416 & & & & \\
\hline \multicolumn{7}{|c|}{ Biases for hidden layer and output layer } \\
\hline Node \# & Bias & & & & & \\
\hline 7 & -3.9144 & & & & & \\
\hline 8 & 0.3585 & & & & & \\
\hline 9 & 1.6993 & & & & & \\
\hline
\end{tabular}

Drilled shafts model has 3 layers:

Input layer has five nodes (Nodes \# 1 to 5)

Hidden layer has three nodes (Nodes \# 6 to 8)

Output layer has one node (Node \# 9)

\begin{tabular}{|c|c|c|c|c|c|}
\hline Node \# & 1 & 2 & 3 & 4 & 5 \\
\hline 6 & 1.5979 & 4.2198 & -0.9423 & -0.1032 & 0.3122 \\
\hline 7 & -0.8261 & -1.7979 & -0.8873 & -0.07553 & -0.1480 \\
\hline 8 & -1.1525 & 0.9636 & -1.9092 & -1.1070 & -1.5575 \\
\hline \multicolumn{6}{|c|}{ Weights from hidden layer to output layer } \\
\hline Node \# & 6 & 7 & 8 & & \\
\hline 9 & 3.3637 & -4.2231 & -3.3358 & & \\
\hline \multicolumn{6}{|c|}{ Biases for hidden layer and output layer } \\
\hline Node \# & Bias & & & & \\
\hline 6 & -5.6394 & & & & \\
\hline 7 & -0.1257 & & & & \\
\hline 8 & 3.2681 & & & & \\
\hline 9 & 1.6731 & & & & \\
\hline
\end{tabular}

